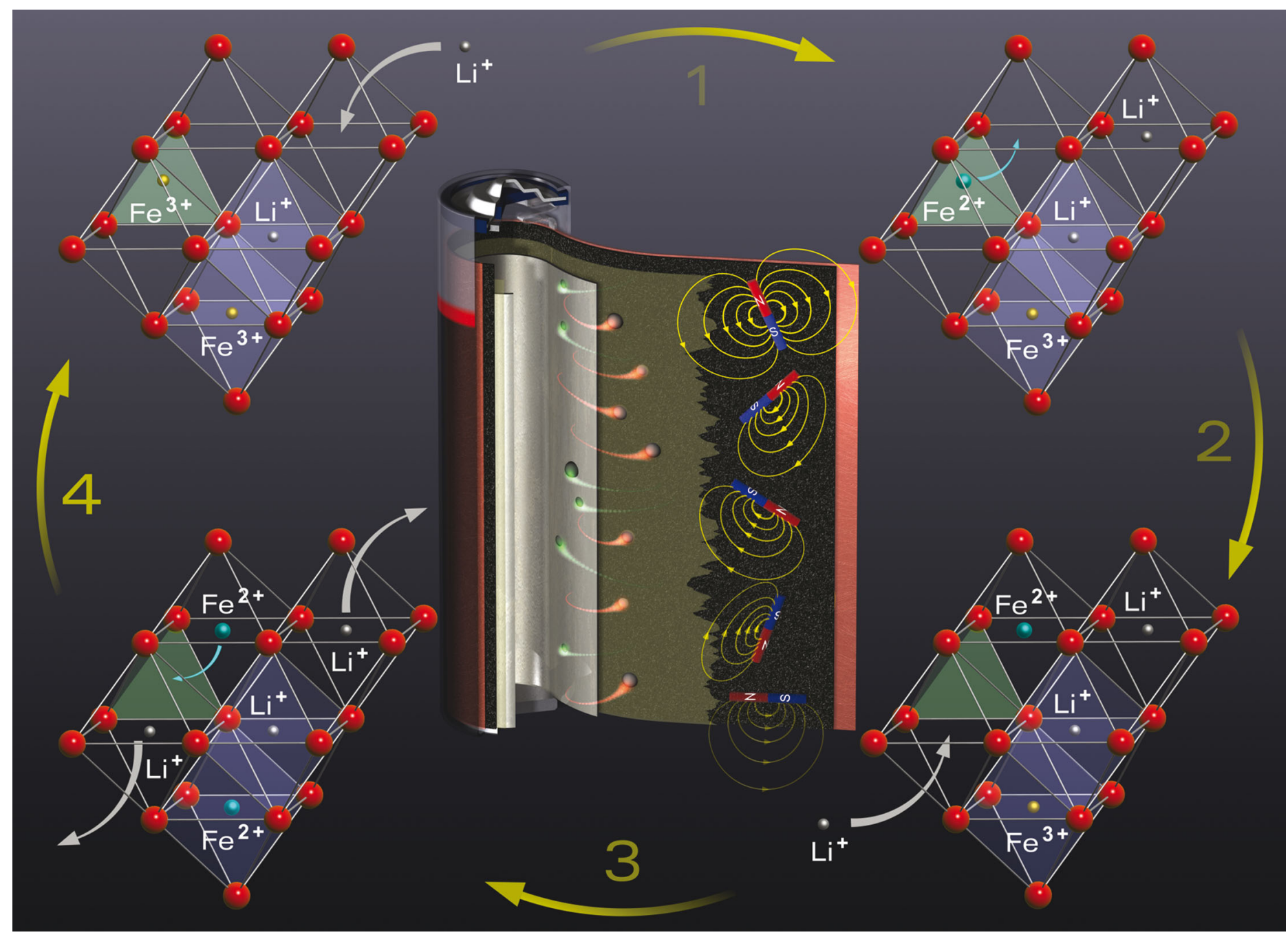

Showcasing research from Dr Torsten Brezesinski's group, Institute of Nanotechnology, Karlsruhe Institute of Technology, Germany

In situ tuning of magnetization via topotactic lithium insertion in ordered mesoporous lithium ferrite thin films

The self-assembly synthesis of large-pore mesoporous $\alpha-\mathrm{LiFe}_{5} \mathrm{O}_{8}$ thin films is presented. This nanocrystalline spinel material can reversibly store charge via topotactic Li insertion which allows tuning of the bulk magnetic properties at room temperature.

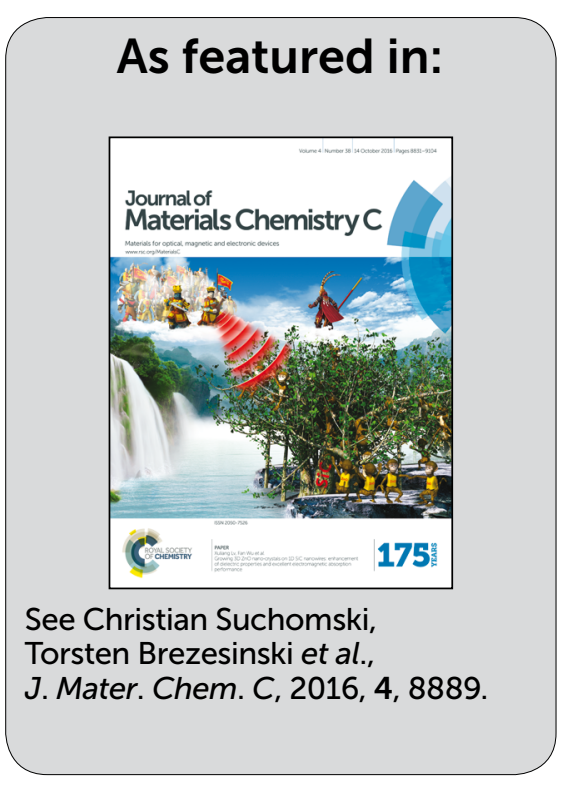




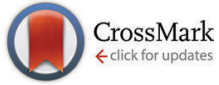

Cite this: J. Mater. Chem. C, 2016 , 4, 8889

Received 1st July 2016 , Accepted 30th July 2016

DOI: $10.1039 / \mathrm{c} 6 \mathrm{tc} 02731 \mathrm{~h}$

www.rsc.org/MaterialsC

\section{In situ tuning of magnetization via topotactic lithium insertion in ordered mesoporous lithium ferrite thin films $\dagger$}

\author{
Christian Reitz, $\ddagger^{\mathrm{a}}$ Christian Suchomski, $\ddagger^{{ }^{\mathrm{b}}}$ Di Wang, ${ }^{\text {ac }}$ Horst Hahn ${ }^{\text {ad }}$ and \\ Torsten Brezesinski*a
}

\begin{abstract}
The synthesis and characterization of cubic mesostructured lithium ferrite $\left(\alpha-\mathrm{LiFe}_{5} \mathrm{O}_{8}\right)$ with $20 \mathrm{~nm}$ diameter pores and nanocrystalline walls is reported. The material is prepared in the form of thin films by sol-gel dip-coating using a poly(isobutylene)-block-poly(ethylene oxide) amphiphilic diblock copolymer as the porogen. Electron microscopy, X-ray scattering and diffraction, time-of-flight secondary ion mass spectrometry, Raman and $\mathrm{X}$-ray photoelectron spectroscopy all show that $\alpha$ - $\mathrm{LiFe}_{5} \mathrm{O}_{8}$ can be templated to produce high-quality films that are chemically and phase-pure and thermally stable to over $600{ }^{\circ} \mathrm{C}$. Magnetometry measurements indicate ferrimagnetic behavior below $300 \mathrm{~K}$, with the coercivity exhibiting a $T^{1 / 2}$ dependence. This novel mesoporous spinel material - when used as an electrode in secondary battery cells - can reversibly store charge via topotactic Li insertion, which allows for the intriguing possibility of tuning the magnetization at room temperature in a facile and controlled manner. The general approach is simple and should be applicable to a variety of other magnetic materials that are capable of reacting electrochemically with $\mathrm{Li}$ to produce reduced phases.
\end{abstract}

\section{Introduction}

Synthetic ferrites such as $\mathrm{Y}_{3} \mathrm{Fe}_{5} \mathrm{O}_{12}$ (garnet), $\mathrm{BaFe}_{12} \mathrm{O}_{19}$ (hexaferrite) and $\mathrm{Mn}_{1-x} \mathrm{Zn}_{x} \mathrm{Fe}_{2} \mathrm{O}_{4}$ (spinel) represent a ubiquitous class of hard and soft-magnetic materials that are widely used in various applications. ${ }^{1,2}$ Herein, we focus on lithium ferrite, $\mathrm{LiFe}_{5} \mathrm{O}_{8}$ (referred to as LFO in the following), which has been shown to exhibit a high magnetization ( $2.5 \mu_{\mathrm{B}}$ per formula unit) and one of the highest Curie temperatures of all spinel ferrites, a narrow resonance linewidth and high electrical resistivity, making it promising for microwave and magnetic device applications. ${ }^{3-5}$

\footnotetext{
${ }^{a}$ Institute of Nanotechnology, Karlsruhe Institute of Technology,

Hermann-von-Helmholtz-Platz 1, 76344 Eggenstein-Leopoldshafen, Germany.

E-mail: torsten.brezesinski@kit.edu

${ }^{b}$ Institute of Physical Chemistry, Justus-Liebig-University Giessen,

Heinrich-Buff-Ring 17, 35392 Giessen, Germany.

E-mail: christian.suchomski@phys.chemie.uni-giessen.de

${ }^{c}$ Institute of Nanotechnology, Karlsruhe Nano Micro Facility,

Karlsruhe Institute of Technology, Hermann-von-Helmholtz-Platz 1,

76344 Eggenstein-Leopoldshafen, Germany

${ }^{d}$ KIT-TUD Joint Research Laboratory Nanomaterials, Institute of Material Science,

Technical University of Darmstadt, Jovanka-Bontschits-Str. 2, 64287 Darmstadt, Germany

$\dagger$ Electronic supplementary information (ESI) available: Additional SEM/TEM images, Raman analysis, XPS spectra, magnetic hysteresis curves, CAD drawing of the SQUID cell, and data from magnetization tuning. See DOI: 10.1039/c6tc02731h

\$ These authors contributed equally.
}

Furthermore, LFO has attracted interest as a low-cost cathode active material for rechargeable Li-ion batteries in the past. ${ }^{6}$ LFO exists in two crystal forms, the "ordered" alpha phase with space group $P_{3} 32$ (or enantiomorphic $P 4_{1} 32$ ) and the "disordered" beta phase with space group $F d \overline{3} m .^{7,8}$ A phase change in the material occurs at temperatures above $730{ }^{\circ} \mathrm{C}$, with a transformation from the alpha phase to the beta phase (order/disorder transition). ${ }^{9,10}$

In recent years, it has been shown that material properties can be tailored by microstructural engineering and controlling the physical dimensions and shape to meet a specific application. However, the synthesis of single-phase and small grain size LFO has proven to be difficult in practice. This is due, in part, to both the formation of impurity phases such as $\alpha-\mathrm{Fe}_{2} \mathrm{O}_{3}$ or $\mathrm{LiFeO}_{2}$ during annealing and the high volatility of lithium (or $\mathrm{Li}_{2} \mathrm{O}$ ) and oxygen loss. ${ }^{11,12}$ In this work, we demonstrate a simple synthetic route to large-pore mesoporous alpha-LFO thin films with nanocrystalline walls by utilizing an evaporationinduced self-assembly (EISA) process.

The EISA process was introduced in the late 1990's and has led to the fabrication of many important phases and materials, most of them being either siliceous in nature or binary metal oxides. ${ }^{13-23}$ Despite the progress made, particularly in the past decade, the preparation of mixed-metal oxides that combine features such as high crystallinity and thermal stability as well as well-developed nanoscale porosity is very challenging. 
Here, we make use of the superior templating properties of a large poly(isobutylene)-block-poly(ethylene oxide) amphiphilic diblock copolymer structure-directing agent to achieve chemically and phase-pure alpha-LFO films with cubic pore symmetry. ${ }^{24-27}$ Notably, they show no signs of major structural degradation or crack formation during the thermal crystallization process and further exhibit stable magnetic properties at room temperature, unlike other templated mesostructured spinel ferrites. ${ }^{28-32}$

These key properties and the fact that LFO can reversibly take up $\mathrm{Li}$ in a topotactic way in a specific voltage range make the films an ideal model system for studying in situ changes in magnetization upon lithiation. Usually, the magnetic properties can only be tuned by strain mediation or electrostatic charge carrier doping, both of which requires precise interface and interphase engineering. ${ }^{27,33-37}$ The mesoporous morphology of the sol-gel derived material is beneficial as it provides short diffusion path lengths for facile $\mathrm{Li}$ insertion, while the film geometry paves the way to novel device structures and concepts (e.g., for future non-volatile memory and logic applications). Similar non-destructive approaches have been reported recently by Tsuchiya et al. and Dasgupta et al. for all-solid-state thin film Li-ion batteries with 10 nm-thick $\mathrm{Fe}_{3} \mathrm{O}_{4}$ anode layer and $\mathrm{Li}$ half-cells with $\gamma-\mathrm{Fe}_{2} \mathrm{O}_{3}$ electrode containing polymer binder and carbon black additive, respectively. ${ }^{38,39}$

Collectively, we show that topotactic Li insertion into LFO allows for the intriguing possibility of controlling the bulk magnetic state in a highly reversible manner and that this electrochemically mediated approach has great potential in the development of tailored magnetic nanostructures.

\section{Experimental section}

\section{Materials}

$\mathrm{Li}\left(\mathrm{OOCCH}_{3}\right)(99.95 \%), \mathrm{Fe}\left(\mathrm{NO}_{3}\right)_{3} \times 9 \mathrm{H}_{2} \mathrm{O}(\geq 99.999 \%)$, lithium bis(trifluoromethanesulfonyl)imide (LiTFSI, 99.95\%), 1-ethyl-3methylimidazolium bis(trifluoromethanesulfonyl)imide (EMIMTFSI, $\geq 97.0 \%$ ), ethanol (EtOH, ACS reagent), tetrahydrofuran (THF, $\geq 99.9 \%$ ) and 2-methoxyethanol (99.8\%) were purchased from Sigma-Aldrich. $\mathrm{H}\left[\mathrm{C}\left(\mathrm{CH}_{3}\right)_{2} \mathrm{CH}_{2}\right]_{107} \mathrm{C}_{6} \mathrm{H}_{4}\left(\mathrm{OCH}_{2} \mathrm{CH}_{2}\right)_{150} \mathrm{OH}\left(\mathrm{PIB}_{107^{-}}\right.$ $b$ - $\mathrm{PEO}_{150}$ ) was obtained from BASF $\mathrm{SE}$ and used as received. $700 \mu \mathrm{m}$-thick $\mathrm{Si}(001)$ wafers were purchased from SiMat.

\section{LFO film synthesis}

$\mathrm{PIB}_{107}-b-\mathrm{PEO}_{150}(45 \mathrm{mg}), \mathrm{Fe}\left(\mathrm{NO}_{3}\right)_{3} \times 9 \mathrm{H}_{2} \mathrm{O}(454.5 \mathrm{mg})$ and $\mathrm{Li}\left(\mathrm{OOCCH}_{3}\right)(14.8 \mathrm{mg})$ were dissolved in a mixed solvent of EtOH (1.5 mL), THF (0.2 mL) and 2-methoxyethanol (0.5 mL). Films were prepared by dip-coating at $25{ }^{\circ} \mathrm{C}$ and $12 \%$ relative humidity onto $\mathrm{Si}(001)$, indium tin oxide $\left(\mathrm{In}_{2} \mathrm{O}_{3} / \mathrm{SnO}_{2}, 90: 10 \mathrm{wt} \%\right.$, ITO)-coated $\mathrm{Si}(001)$ and quartz glass substrates. After drying for $5 \mathrm{~min}$, the as-made films were transferred to an oven at $130{ }^{\circ} \mathrm{C}$ for $1 \mathrm{~h}$ and then heated to $300{ }^{\circ} \mathrm{C}\left(0.5{ }^{\circ} \mathrm{C} \mathrm{min}{ }^{-1}\right)$, followed by aging for $12 \mathrm{~h}$. Finally, they were heated to $630{ }^{\circ} \mathrm{C}\left(10{ }^{\circ} \mathrm{C} \mathrm{min}^{-1}\right)$ both to burn out the polymer structure-directing agent and to crystallize the wall structure.

\section{Cell assembly}

Half-cells were assembled in an argon-filled glovebox by stacking $600 \mu$ m-thick Li metal foil (China Lithium Ltd), GF/A separator (GE Healthcare Life Sciences, Whatman) and mesoporous LFO film on ITO-coated $\mathrm{Si}(001)$ substrate. The electrolyte used was a solution of LiTFSI (20 wt\%) in EMIM-TFSI. The water content was $<10 \mathrm{ppm}$, as determined by Karl Fischer titration.

\section{Instrumentation}

Scanning electron microscopy (SEM) images were collected on a MERLIN from Carl Zeiss operated at $5 \mathrm{keV}$. Transmission electron microscopy (TEM) imaging was performed on an aberration corrected Titan 80-300 (FEI) equipped with an energy-dispersive X-ray spectroscopy (EDX) detector and Gatan Tridiem image filter. The microscope was operated at $300 \mathrm{keV}$ in TEM mode for high-resolution TEM (HRTEM) and in nanoprobe mode for scanning TEM (STEM). X-ray diffraction (XRD) was carried out on an X'Pert PRO from PANalytical instruments $(\lambda=0.15418 \mathrm{~nm})$ equipped with an X'Celerator RTMS detector. Grazing incidence small-angle X-ray scattering (GISAXS) measurements were conducted at the German synchrotron radiation facility HASYLAB at DESY $\left(\lambda=0.1088 \mathrm{~nm}\right.$, beam size $=22.6 \times 23.3 \mu \mathrm{m}^{2}$, sample $/$ detector distance $=3787 \mathrm{~mm}$ ) by use of a DECTRIS Pilatus $1 \mathrm{M}$ area detector $\left(981 \times 1043\right.$ pixels, pixel size $\left.=172 \times 172 \mu \mathrm{m}^{2}\right)$. The angle of incidence was set to $0.2^{\circ}$. For data analysis, DPDAK 1.2.0 software was used. $^{40} \mathrm{X}$-ray photoelectron spectroscopy (XPS) data were acquired on a PHI VersaProbe scanning XPS microprobe equipped with a monochromatic Al-K $\alpha$ source and hemispherical electron energy analyzer. The electron takeoff angle was set to $45^{\circ}$ and the $\mathrm{C} 1 \mathrm{~s}$ peak at $284.8 \mathrm{eV}$ was used as an energy reference to correct for charging. Time-of-flight secondary ion mass spectrometry (TOF-SIMS) was performed on a TOF-SIMS 5 from ION-TOF GmbH. A $25 \mathrm{keV} \mathrm{Bi}{ }^{+}$primary ion beam $\left(I=0.06 \mathrm{pA}\right.$, area $=100 \times 100 \mu \mathrm{m}^{2}$, ion dose density $=$ $1.24 \times 10^{12}$ ions per $\mathrm{cm}^{2}$ ) was used to generate secondary ions. For sputter etching, a beam of $1 \mathrm{keV} \mathrm{O}_{2}{ }^{+}(I=254.76 \mathrm{nA}$, area $=$ $200 \times 200 \mu \mathrm{m}^{2}$, ion dose density $=1.34 \times 10^{18}$ ions per $\left.\mathrm{cm}^{2}\right)$ was used. Raman spectra were acquired on a SENTERRA dispersive Raman microscope from Bruker Optics equipped with an Olympus objective $($ MPLN $100 \times$, F.N.22, N.A.0.9) and Nd:YAG laser $(\lambda=532 \mathrm{~nm}, P=2 \mathrm{~mW})$. An MPMS XL-5 superconducting quantum interference device (SQUID) magnetometer from Quantum Design was used for magnetic susceptibility measurements in the field range from +45 to -45 kOe. Cyclic voltammetry was performed in the potential range from 3.2 to $1.4 \mathrm{~V}$ with respect to $\mathrm{Li}^{+} / \mathrm{Li}$ at a scan rate of $1 \mathrm{mV} \mathrm{s}^{-1}$ by use of an Autolab PGSTAT302 potentiostat.

\section{Results and discussion}

The films employed in this work were prepared by dip-coating onto polished substrates, including $\mathrm{Si}(001)$ and ITO-coated $\mathrm{Si}(001)$ wafers and quartz glass. Structural characterization was performed on samples heated to temperatures from 530 to $630{ }^{\circ} \mathrm{C}$ by electron microscopy and GISAXS. Fig. 1 and Fig. S1 (ESI $\dagger$ ) 

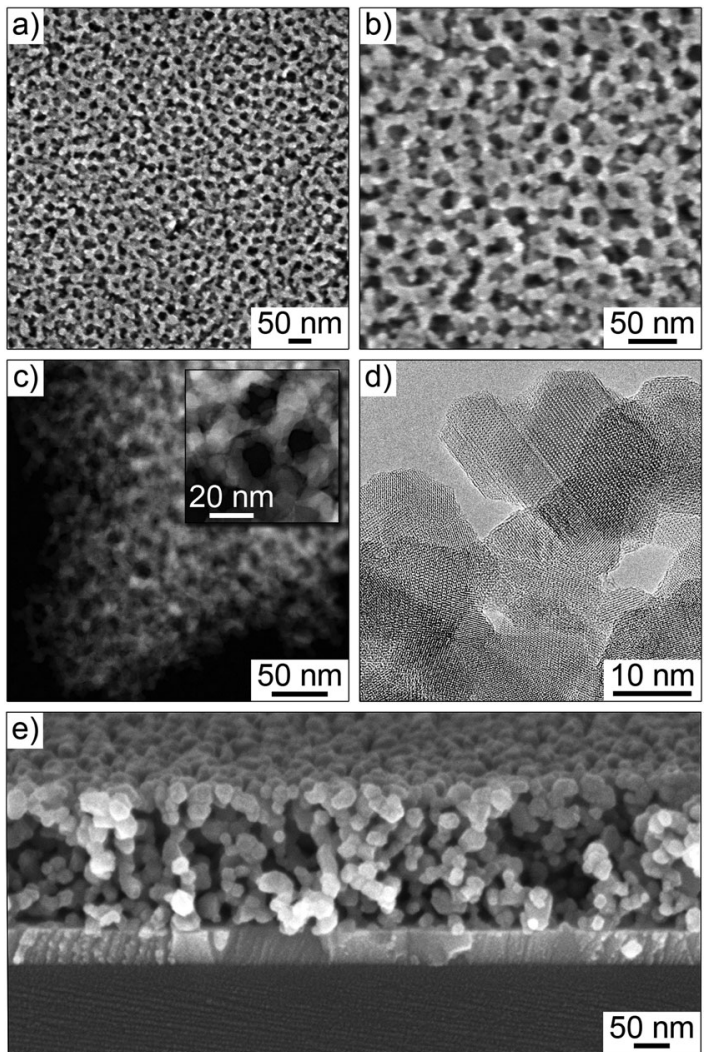

Fig. 1 Electron microscopy of mesoporous LFO thin films on (a-d) Si(001) and (e) ITO-coated $\mathrm{Si}(001)$ substrates heated to $630{ }^{\circ} \mathrm{C}$. (a and b) Top view SEM and (c) Both panel (c) and the inset in (c) show high-angle annular dark-field STEM images at different magnifications. (d) HRTEM image. (e) Cross-sectional SEM image collected with a sample tilt of $80^{\circ}$

show results from TEM and SEM of mesoporous LFO films heated to $630{ }^{\circ} \mathrm{C}$. From these data, we conclude that the selfassembling does not depend on the type of substrate used. Top view SEM images show a partially ordered mesophase with open $20 \mathrm{~nm}$ diameter pores and $10 \mathrm{~nm}$-thick walls. The films appear to be free of cracks and other structural defects, and the network of pores persists throughout the bulk, as shown by cross-sectional SEM. STEM confirms the homogeneity of composition, while HRTEM demonstrates the high crystallinity with walls composed of randomly oriented spinel grains.

Fig. 2 shows synchrotron-based GISAXS patterns at an angle of incident of $0.2^{\circ}$ obtained ex situ on a mesoporous LFO film of thickness around $200 \mathrm{~nm}$ on ITO-coated $\mathrm{Si}(001)$ substrate. Line cuts along the highest intensity in $\boldsymbol{q}_{y}$ are also shown in the figure. Oscillations and strong in-plane scattering maxima from the ITO layer and LFO, respectively, are clearly visible. The primary reasons for the lack of scattering in $\boldsymbol{q}_{z}$ are the low film thickness and that the material is already crystalline to some degree after heating to $530{ }^{\circ} \mathrm{C}$ and the pore ordering is lower than that of other polymer-templated mesostructured spinel ferrites reported in the literature. ${ }^{41}$ However, given that $\mathrm{Li}$ compounds in general are rather poor sol-gel precursors (glass formers), it is quite remarkable that LFO films with both a well-defined pore structure and uniform composition can be
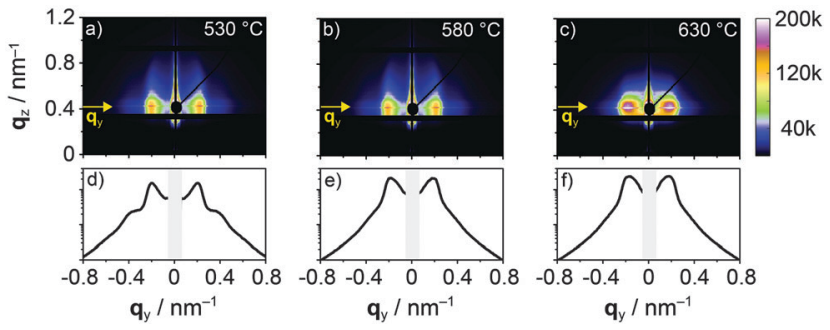

Fig. $2(\mathrm{a}-\mathrm{c})$ Synchrotron-based GISAXS patterns of a mesoporous LFO thin film on ITO-coated $\mathrm{Si}(001)$ substrate heated to different temperatures of (a) $530{ }^{\circ} \mathrm{C}$, (b) $580{ }^{\circ} \mathrm{C}$ and (c) $630{ }^{\circ} \mathrm{C}$. The corresponding intensity color map is shown on the right. $(\mathrm{d}-\mathrm{f})$ Horizontal line cuts along the $\boldsymbol{q}_{y}$-direction indicated by the yellow arrows.

produced by facile coassembly strategies. As seen, the full width at half maximum (FWHM) of the first order peak at $\boldsymbol{q}_{y}=0.195 \mathrm{~nm}^{-1}$ increases and the second order peak decreases in intensity with an increase in heating temperature to $630{ }^{\circ} \mathrm{C}$. This can be attributed to distortions induced by crystallization and grain growth. Severe structural degradation is observed at temperatures equal to or above $700{ }^{\circ} \mathrm{C}$. Also, it can be seen that the in-plane lattice contraction is negligible, which helps explain why the films are crack-free on the micrometer level. Collectively, the GISAXS data agree with the results from electron microscopy that LFO can be templated to produce thermally stable films with a cubic pore network.

The crystallization behavior was investigated by means of XRD (Fig. 3a). The onset of crystallization was found to be at $510{ }^{\circ} \mathrm{C}$, and the reflections can be indexed to the alpha phase of LFO. The average crystallite size was calculated from the FWHM of the (220) and (311) reflections at $30.5^{\circ}$ and $35.7^{\circ} 2 \theta$, respectively, by use of the Scherrer equation. This analysis provides values ranging from $(7 \pm 1) \mathrm{nm}$ at $530{ }^{\circ} \mathrm{C}$ to $(11 \pm 1) \mathrm{nm}$ at $630{ }^{\circ} \mathrm{C}$. On the basis of $\mathrm{XRD}$, the presence of second phases such as $\alpha-\mathrm{Fe}_{2} \mathrm{O}_{3}, \mathrm{LiFeO}_{2}$ or other ferric oxides can be ruled out. These could potentially be formed in the Fe-rich material, particularly at elevated temperatures. ${ }^{42}$ Overall, this finding is exciting because phase-pure LFO can usually only be achieved by prolonged heating well above $700{ }^{\circ} \mathrm{C}$, which, however, is detrimental to maintaining nanoscale features due to sintering effects. We believe that the mesoporous morphology characterized by very thin walls is beneficial for the control of the amorphous to crystalline transformation.

The phase composition was also investigated via Raman spectroscopy. According to group theory, alpha-LFO has forty Raman-active phonon modes $\left(6 \times \mathrm{A}_{1}+14 \times \mathrm{E}+20 \times \mathrm{F}_{2}\right)$, while beta-LFO possesses only five symmetry allowed first-order modes $\left(1 \times \mathrm{A}_{1 \mathrm{~g}}+1 \times \mathrm{E}_{\mathrm{g}}+3 \times \mathrm{F}_{2 \mathrm{~g}}\right){ }^{43,44}$ A representative nonpolarized Raman spectrum obtained on a mesoporous LFO film on quartz glass substrate heated to $630{ }^{\circ} \mathrm{C}$ is shown in Fig. $3 \mathrm{~b}$. In total, eighteen bands are observed between 100 and $900 \mathrm{~cm}^{-1}$, the peak frequencies of which are consistent with those reported for single crystals of alpha-LFO (see Table S1, ESI $\dagger$ ). ${ }^{44}$ The lack of Raman bands is probably due to superposition of the spectrum from the substrate as well as line broadening and decreasing intensity because of the small crystallite size (phonon confinement). ${ }^{45,46}$ Nevertheless, the data neither 

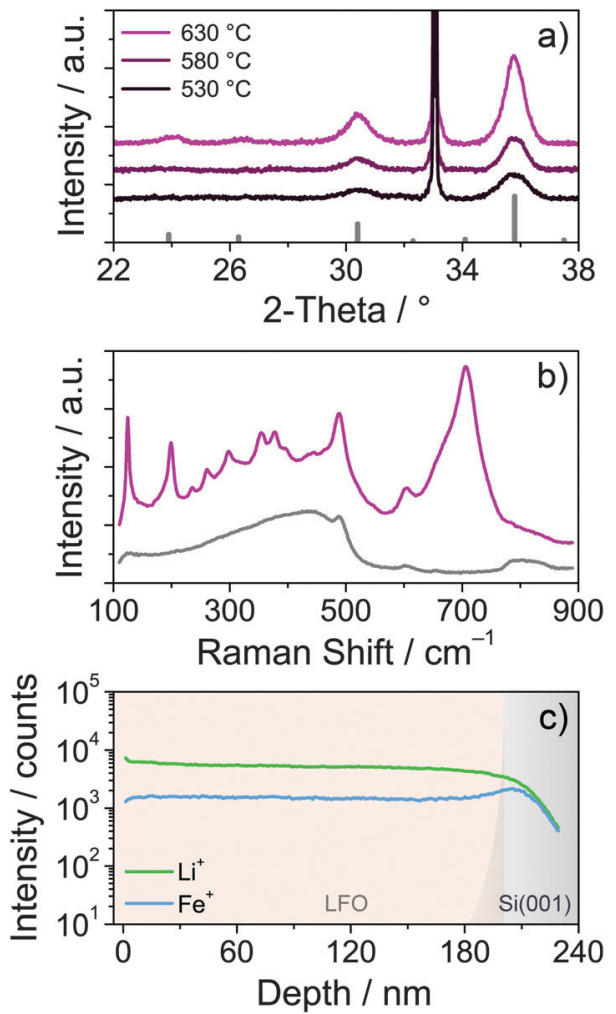

Fig. 3 Crystallinity and phase composition of mesoporous LFO thin films. (a) XRD patterns for different heating temperatures. The line pattern corresponds to ICSD reference card no. 35769 for alpha-LFO.? (b) Raman spectra obtained on a bare quartz glass (gray) and mesoporous LFO film on quartz glass (magenta) heated to $630{ }^{\circ} \mathrm{C}$. (c) TOF-SIMS depth profiling showing ${ }^{7} \mathrm{Li}^{+}$and ${ }^{56} \mathrm{Fe}^{+}$.

indicate polymorphism nor the presence of second phases, thus confirming purity of the sol-gel derived material.

TOF-SIMS was used to obtain information on the spatial distribution of $\mathrm{Li}$ and Fe. Depth profiling results are shown in Fig. 3c. Both the ${ }^{7} \mathrm{Li}^{+}$and ${ }^{56} \mathrm{Fe}^{+}$signals are constant, which implies that the metal ions are homogeneously distributed throughout the bulk of the films. Minor variations are observed in the vicinity of the sample/substrate interface. This is likely due, in part, to the different chemical environment, which strongly affects the ionization probability.

Although XPS is not suited to determine the atomic Li/Fe ratio because of the relatively low amount of lithium in LFO and the fact that the Li 1s and Fe 3p levels are superimposed, this technique was applied to gain insight into the oxidation state of iron and the bonding state of oxygen. Fig. S2 (ESI $\dagger$ ) shows both a survey spectrum and detailed scans of the Fe $2 \mathrm{p}$ and $\mathrm{O} 1 \mathrm{~s}$ regions. Apart from a weak $\mathrm{Si} 2 \mathrm{p}$ substrate peak, only $\mathrm{Fe}, \mathrm{Li}, \mathrm{O}$ and $\mathrm{C}$ levels are clearly visible. The Fe $2 \mathrm{p}$ data establish that iron is - as expected - in the oxidation state +3 . The $\mathrm{O} 1 \mathrm{~s}$ data indicate two different bonding states, corresponding to lattice oxygen and hydroxyl oxygen. The presence of $\mathrm{OH}$ groups is not unexpected because, after synthesis, the mesoporous films were stored at ambient conditions. Given that the wall thickness and XPS information depth are similar, the results can be considered representative of the whole sample.
In a nutshell, the data in Fig. 3 and Fig. S2 (ESI†) demonstrate that the crystallite size is on the same order as the wall thickness after heating to $630{ }^{\circ} \mathrm{C}$ and the films are single-phase with no major fluctuations in composition.

The magnetic properties of the mesoporous LFO films heated to $630{ }^{\circ} \mathrm{C}$ were studied by DC SQUID magnetometry. Fig. 4a shows zero-field-cooled (ZFC) and field-cooled (FC) curves measured at 100 Oe with the magnetic field oriented parallel to the substrate plane. The magnetization increases as the temperature is increased until a broad maximum is reached at about $310 \mathrm{~K}$, which can be associated with the blocking temperature, $T_{\mathrm{B}}$. In this temperature range and above the thermal energy overcomes the magnetic coupling forces, resulting in superparamagnetic relaxation. Fig. 4b shows in-plane hysteresis curves at different temperatures. $M(H)$ loops measured at 5 and $300 \mathrm{~K}$ with the magnetic field oriented parallel as well as perpendicular to the substrate plane are shown in Fig. S3 (ESI†). From the latter data, it is inferred that the films have the magnetic easy axis in the plane. This means the energy needed to reach "saturation magnetization" is higher in the off-plane direction, which can be well-explained by the shape anisotropy. The in-plane and out-of-plane hysteresis curves indicate soft-magnetic behavior below $300 \mathrm{~K}$ with moderate low-temperature coercivities, $H_{\mathrm{C}}$, of 360 Oe and 430 Oe, respectively.

Fig. $4 \mathrm{~b}$ further shows that $H_{\mathrm{C}}$ decreases with increasing temperature and exhibits a $T^{1 / 2}$ dependence. This kind of
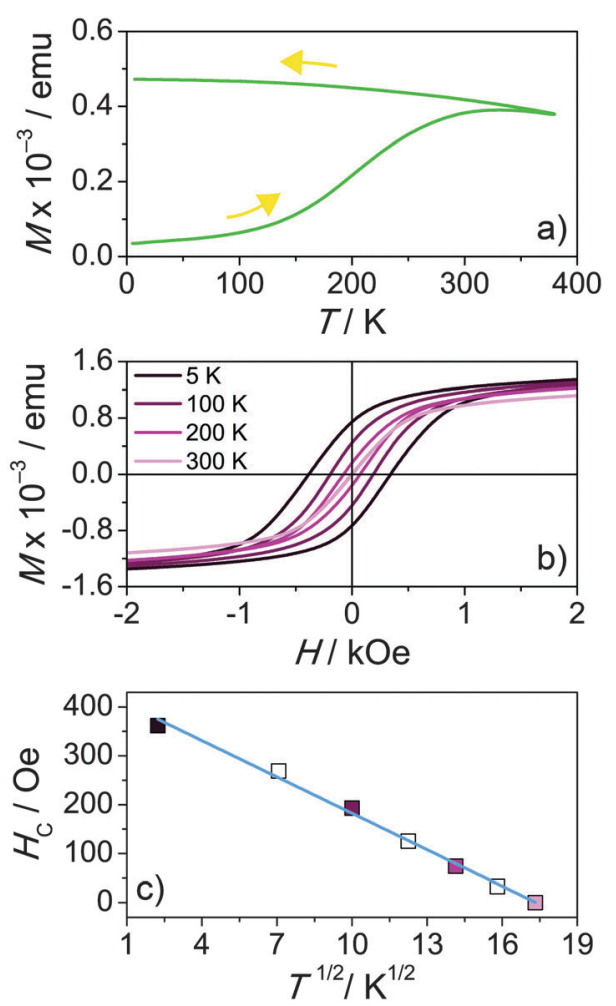

Fig. 4 In-plane magnetic properties of mesoporous LFO thin films. (a) ZFC/FC curves measured in an applied field of $100 \mathrm{Oe}$. (b) Hysteresis curves within the field range of $\pm 2 \mathrm{kOe}$ at different temperatures of $5 \mathrm{~K}, 100 \mathrm{~K}, 200 \mathrm{~K}$ and $300 \mathrm{~K}$. (c) Plot of $H_{C}$ vs. $T^{1 / 2}$. The blue line is a linear fit to the data. 
dependence is usually observed for non-interacting singledomain particles below $T_{\mathrm{B}} \cdot{ }^{47-49}$ Fig. $4 \mathrm{c}$ presents a linear fit of the $H_{\mathrm{C}}$ data against $T^{1 / 2}$ according to the expression:

$$
H_{\mathrm{C}}=H_{\mathrm{C}}(0)\left[1-\left(\frac{T}{T_{\mathrm{B}}}\right)^{1 / 2}\right]
$$

where $H_{\mathrm{C}}(0)$ is the coercivity at zero temperature. ${ }^{50}$ From this fit, we obtain $T_{\mathrm{B}} \approx 305 \mathrm{~K}$, in agreement with the non-hysteretic behavior observed for $T>300 \mathrm{~K}$ (see $M(H)$ curve at $350 \mathrm{~K}$ in Fig. S3, ESI $\dagger$ ). We note that the magnetic transition temperature could not be determined. The reason is that it is evidently well above $380 \mathrm{~K}$, and thus out of the temperature range of our magnetometer.

Spinel ferrites have been shown to undergo conversion reactions at low potential when used as an anode material in Li-ion batteries. ${ }^{51-53}$ These electrochemical reactions are not fully reversible and lead to large volume changes and significant hysteresis between charge and discharge, which is partly why they will likely not be used in practical (next-generation) energy storage devices, despite high theoretical specific capacities. However, in recent years, it has been shown that spinel ferrites such as $\mathrm{ZnFe}_{2} \mathrm{O}_{4}$ can store $\mathrm{Li}$ via topotactic insertion at relatively high potentials $\left(\geq 1.0 \mathrm{~V}\right.$ with respect to $\left.\mathrm{Li}^{+} / \mathrm{Li}\right) .{ }^{54-56}$ This should allow for the possibility of modulating the magnetization in a facile and reversible manner, which makes them well-suited model materials for such studies, particularly those that exhibit room temperature magnetic properties.

All magnetization modulation experiments were carried out in situ in a SQUID magnetometer at room temperature and in an applied field of 100 Oe (see CAD drawing of the home-built cell in Fig. S4, ESI $\dagger$ ). Li half-cells were assembled by using LiTFSI in EMIM-TFSI as the electrolyte. An ionic liquid-based electrolyte was chosen because of the low vapor pressure, allowing measurements under reduced pressure. Fig. 5a shows a representative cyclic voltammogram between 3.2 and $1.4 \mathrm{~V}$ with respect to $\mathrm{Li}^{+} / \mathrm{Li}$ at a scan rate of $1 \mathrm{mV} \mathrm{s}{ }^{-1}$ collected after some cycles when the performance reached a stable level (see also voltammetry sweeps in Fig. S5, ESI $\dagger$ ).

The mesoporous LFO films exhibit pronounced redox peaks at about $1.6 \mathrm{~V}$ (cathodic) and $1.9 \mathrm{~V}$ (anodic), thereby indicating the presence of distinct Li insertion sites. The overall shape of the cyclic voltammogram is consistent with that of other Fe-based oxides. ${ }^{41,57}$ A small cathodic current is observed between 3.2 and $1.9 \mathrm{~V}$. According to experimental results and first-principles modelling, ${ }^{57,58} \mathrm{Li}$ uptake in this potential range leads to the reduction of tetrahedral $\mathrm{Fe}^{3+}$ ions. Because $\mathrm{Fe}^{2+}$ ions have a larger radius, the tetrahedral sites become unfavorable, and thus they either exchange places with octahedral $\mathrm{Li}^{+}$ions or hop to vacant neighboring (octahedral) sites. ${ }^{38,59}$ The latter scenario appears more likely since $\mathrm{Li}_{3} \mathrm{Fe}_{5} \mathrm{O}_{8}$ with space group $\mathrm{P}_{3} 32$, which is apparently an intermediate in the electrochemical reaction of $\mathrm{LFO}$ with $\mathrm{Li}$, has both $\mathrm{Fe}$ and $\mathrm{Li}$ ions residing solely on octahedral sites.

A schematic of the Li insertion/extraction into/from alphaLFO is shown in Fig. 6. With increasing population of Fe ions
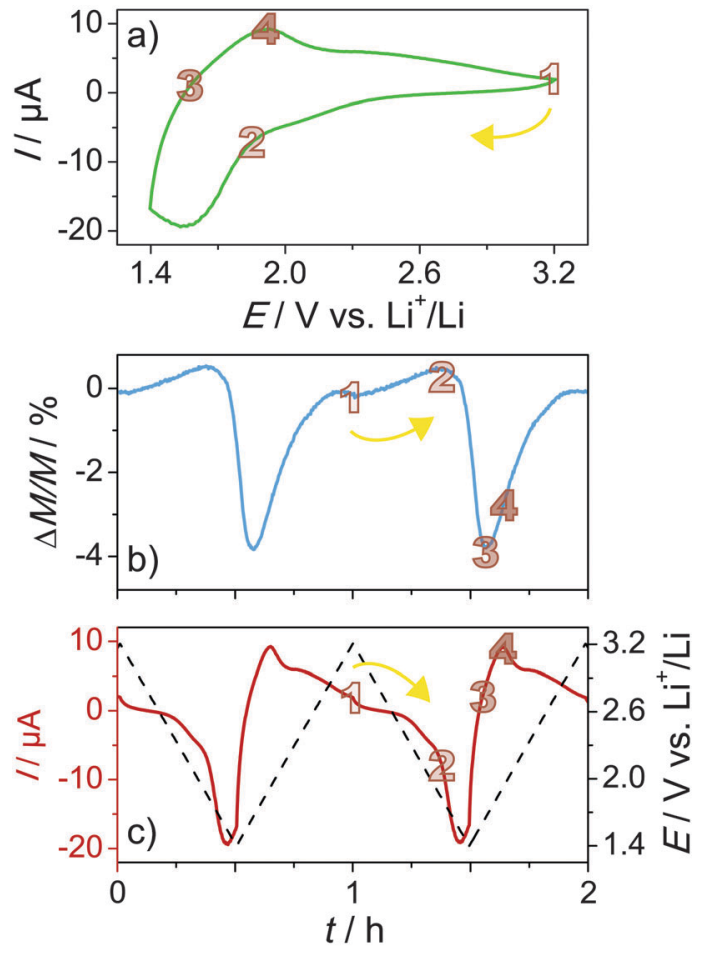

Fig. 5 In situ tuning of magnetization via electrochemical Li insertion into mesoporous LFO thin films. (a) Cyclic voltammogram at a scan rate of $1 \mathrm{mV} \mathrm{s}{ }^{-1}$. (b) Relative change in magnetization at room temperature measured in an applied field of 100 Oe and (c) corresponding potential (dashed line) and current (red line) versus the time.

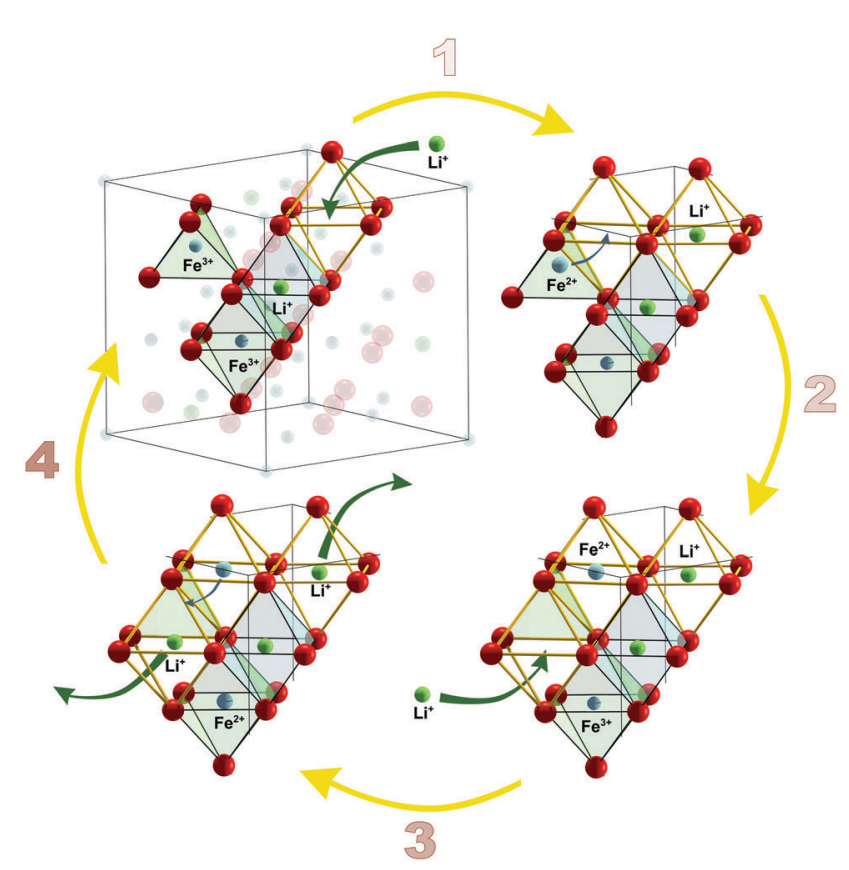

Fig. 6 Schematic of the topotactic Li insertion/extraction into/from LFO during potentiodynamic cycling in the 3.2 to $1.4 \mathrm{~V}$ range with respect to $\mathrm{Li}^{+} / \mathrm{Li}$. (1) Tetrahedral $\mathrm{Fe}^{3+}$ ions are reduced and (2) likely hop to vacant octahedral sites. (3) With further $\mathrm{Li}$ insertion, $\mathrm{Fe}^{3+}$ ions on both the tetrahedral and octahedral sites are reduced, leading to a monotonic decrease in magnetic moment. (4) On reversing the potential sweep (change from cathodic to anodic current), Li is extracted from the spinel lattice and the "initial" state is recovered. 
on octahedral sites, the magnetic moment increases, albeit only slightly (from 1 to 2 in the $\Delta M / M v s$. $t$ curve in Fig. $5 \mathrm{~b}$ ). This is due to altered exchange interactions between the Fe ions in the spinel lattice. Their magnetic moments are coupled by superexchange interaction through intermediate oxygen ions. The inter-sublattice exchange, which is stronger than the intrasublattice exchange, is known to be antiferromagnetic (antiparallel) in nature. However, because the sublattice magnetization is not equal due to the different population of $\mathrm{Fe}$ ions on tetrahedral and octahedral sites $\left(\mathrm{Fe}_{8}{ }^{\text {tet }}\left[\mathrm{Li}_{4} \mathrm{Fe}_{12}\right]^{\text {oct }} \mathrm{O}_{32}\right.$ per unit cell), LFO shows ferrimagnetic behavior. Given that $\mathrm{Fe}^{2+}$ ions apparently only reside on octahedral sites, $\mathrm{Li}$ insertion into the parent material must lead to an increase in magnetic moment. Upon lowering the potential further, a relatively large cathodic peak is seen at about $1.6 \mathrm{~V}$, and the $\mathrm{Fe}^{3+}$ ions on both the octahedral and tetrahedral sites are reduced. This reduction leads to a monotonic decrease in magnetic moment (see Fig. 5b). The lowest moment or, in other words, largest relative change in magnetization is found when the current becomes positive (anodic), as is evident from Fig. $5 \mathrm{~b}$ (from 2 to 3 in the $\Delta M / M v s$. $t$ curve). Then, $\mathrm{Li}$ is extracted from the host lattice and the $\mathrm{Fe}^{2+}$ ions are re-oxidized on the reverse sweep, which is accompanied by an increase in magnetic moment until the "initial" state is recovered. As expected on the basis of the behavior
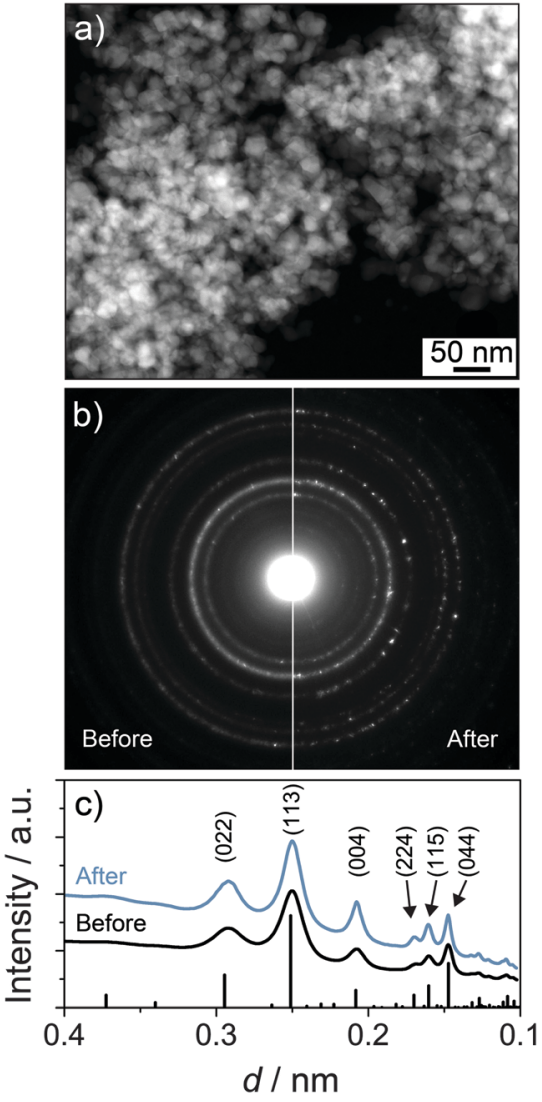

Fig. 7 Electron microscopy of mesoporous LFO thin films in a lithiated state $\left(1.4 \mathrm{~V}\right.$ with respect to $\left.\mathrm{Li}^{+} / \mathrm{Li}\right)$ after 20 cycles. (a) Low-magnification high-angle annular dark-field STEM image. (b) SAED before and after cycling and (c) corresponding radial integration patterns. The line pattern corresponds to ICSD reference card no. 35769 for alpha-LFO. during $\mathrm{Li}$ insertion, the steepest increase occurs between 3 and 4 in the $\Delta M / M v s$. $t$ curve, in line with the current response in Fig. $5 \mathrm{c}$. The measured magnetization modulation is as high as $4 \%$ with $1 \mathrm{mV} \mathrm{s}^{-1}$ of scan rate. More importantly, the process is highly reversible, as can be seen from Fig. 5 and Fig. S5 (ESI $\dagger$ ).

Fig. 7 shows an STEM image of the lithiated LFO material after 20 cycles as well as selected-area electron diffraction (SAED) patterns collected before and after cycling. From these data, it is apparent that the mesoporous structure is little affected because the crystalline phase does not change upon lithiation. The latter can be clearly seen from the radial integration patterns, which also confirm that irreversible microstructural effects (notable grain growth, partial amorphization, etc.) during topotactic $\mathrm{Li}$ insertion/extraction can be ruled out.

Overall, the experimental results are consistent and agree qualitatively with the few data in existence, but further work is needed to confirm the hypotheses. However, we note that more detailed studies by Mössbauer spectroscopy or other state-ofthe-art characterization techniques are difficult because of the low amount of material in polymer-templated mesostructured thin films.

\section{Conclusions}

In summary, we have shown, for the first time, that $\alpha-\mathrm{LiFe}_{5} \mathrm{O}_{8}$ can be templated using large diblock copolymers to produce mesostructured thin films with cubic pore symmetry. As evidenced by different characterization techniques (TEM, GISAXS, XRD, XPS, etc.), the sol-gel derived material is well-defined and shows no signs of impurity phases after thermal crystallization, despite the large Fe excess. Likewise, no signs of major structural changes are observed. The magnetization results indicate ferrimagnetic ordering below $300 \mathrm{~K}$. Cyclic voltammetry and ex situ electron microscopy analysis of the mesoporous $\alpha-\mathrm{LiFe}_{5} \mathrm{O}_{8}$ thin film electrodes in two-electrode Li battery cells using an ionic liquidbased electrolyte indicate that the spinel ferrite can reversibly store $\mathrm{Li}$ in the potential range from 3.2 to $1.4 \mathrm{~V}$ - with the electrochemical reactions proceeding in a topotactic way - which allows control and tuning of the magnetization at room temperature. These results are exciting and show that the approach of reversibly modulating the bulk magnetic properties via facile $\mathrm{Li}$ insertion has potential for the development of novel device concepts and design principles.

\section{Acknowledgements}

We thank Dr Marcus Rohnke and Dr Thomas Leichtweiss for assistance with the TOF-SIMS and XPS measurements, respectively. We also thank Dr Robert Kruk and Dr Subho Dasgupta for fruitful discussions. This work was partly carried out with the support of the Karlsruhe Nano Micro Facility (KNMF), a Helmholtz Research Infrastructure at Karlsruhe Institute of Technology (KIT). Parts of this research were carried out at the light source PETRA III at DESY, a member of the Helmholtz 
Association (HGF). We thank Dr Matthias Schwartzkopf for assistance in using beamline P03. Financial support by the German Academic Exchange Service (T. B.) and the German Research Foundation (H. H., grant no. DA 1781/1-1 and HA 1344/34-1) is gratefully acknowledged.

\section{Notes and references}

1 M. Sugimoto, J. Am. Ceram. Soc., 1999, 82, 269-280.

2 V. G. Harris, IEEE Trans. Magn., 2012, 48, 1075-1104.

3 E. A. Schwabe and D. A. Campbell, J. Appl. Phys., 1963, 34, 1251-1253.

4 G. O. White and C. E. Patton, J. Magn. Magn. Mater., 1978, 9, 299-317.

5 H. J. Masterson, J. G. Lunney, D. Ravinder and J. M. D. Coey, J. Magn. Magn. Mater., 1995, 140, 2081-2082.

6 F. O. Ernst, H. K. Kammler, A. Roessler, S. E. Pratsinis, W. J. Stark, J. Ufheil and P. Novak, Mater. Chem. Phys., 2007, 101, 372-378.

7 A. Tomas, P. Laruelle, J. L. Dormann and M. Nogues, Acta Crystallogr., Sect. C: Cryst. Struct. Commun., 1983, 39, 1615-1617.

8 S. J. Marin, M. Okeeffe and D. E. Partin, J. Solid State Chem., 1994, 113, 413-419.

9 A. Ahniyaz, Solid State Ionics, 2002, 151, 419-423.

10 P. B. Braun, Nature, 1952, 170, 1123.

11 A. J. Pointon and R. C. Saull, J. Am. Ceram. Soc., 1969, 52, 157-160.

12 G. Bandyopadhyay and R. M. Fulrath, J. Am. Ceram. Soc., 1974, 57, 182-186.

13 P. Innocenzi and L. Malfatti, Chem. Soc. Rev., 2013, 42, 4198-4216.

14 B. Smarsly and M. Antonietti, Eur. J. Inorg. Chem., 2006, 1111-1119.

15 C. Sanchez, C. Boissière, D. Grosso, C. Laberty and L. Nicole, Chem. Mater., 2008, 20, 682-737.

16 Y. Deng, J. Wei, Z. Sun and D. Zhao, Chem. Soc. Rev., 2013, 42, 4054-4070.

17 D. Gu and F. Schüth, Chem. Soc. Rev., 2013, 43, 313-344.

18 Y. Ren, Z. Ma and P. G. Bruce, Chem. Soc. Rev., 2012, 41, 4909-4927.

19 D. Grosso, C. Boissière, B. Smarsly, T. Brezesinski, N. Pinna, P. A. Albouy, H. Amenitsch, M. Antonietti and C. Sanchez, Nat. Mater., 2004, 3, 787-792.

20 S. Y. Choi, M. Mamak, N. Coombs, N. Chopra and G. A. Ozin, Adv. Funct. Mater., 2004, 14, 335-344.

21 C. J. Brinker, Y. Lu, A. Sellinger and H. Fan, Adv. Mater., 1999, 11, 579-585.

22 D. Grosso, F. Cagnol, G. J. de A. A. Soler-Illia, E. L. Crepaldi, H. Amenitsch, A. Brunet-Bruneau, A. Bourgeois and C. Sanchez, Adv. Funct. Mater., 2004, 14, 309-322.

23 G. A. Ozin, K. Hou, B. V. Lotsch, L. Cademartiri, D. P. Puzzo, F. Scotognella, A. Ghadimi and J. Thomson, Mater. Today, 2009, 12, 12-23.
24 T. von Graberg, P. Hartmann, A. Rein, S. Gross, B. Seelandt, C. Röger, R. Zieba, A. Traut, M. Wark, J. Janek and B. M. Smarsly, Sci. Technol. Adv. Mater., 2011, 12, 025005.

25 C. Weidmann, K. Brezesinski, C. Suchomski, K. Tropp, N. Grosser, J. Haetge, B. M. Smarsly and T. Brezesinski, Chem. Mater., 2012, 24, 486-494.

26 P. Hartmann, D. Lee, B. M. Smarsly and J. Janek, ACS Nano, 2010, 4, 3147-3154.

27 C. Reitz, P. M. Leufke, R. Schneider, H. Hahn and T. Brezesinski, Chem. Mater., 2014, 26, 5745-5751.

28 C. Reitz, C. Suchomski, J. Haetge, T. Leichtweiss, Z. Jagličić, I. Djerdj and T. Brezesinski, Chem. Commun., 2012, 48, 4471-4473.

29 C. Reitz, C. Suchomski, V. S. K. Chakravadhanula, I. Djerdj, Z. Jagličić and T. Brezesinski, Inorg. Chem., 2013, 52, 3744-3754.

30 M. Bagheri, M. A. Bahrevar and A. Beitollahi, Ceram. Int., 2015, 41, 11618-11624.

31 M. Gu, B. Yue, R. Bao and H. He, Mater. Res. Bull., 2009, 44, 1422-1427.

32 Y. Wang, H. Zhao, M. Li, J. Fan and G. Zhao, Appl. Catal., B, 2014, 147, 534-545.

33 P. Leufke, R. Kruk, R. Brand and H. Hahn, Phys. Rev. B: Condens. Matter Mater. Phys., 2013, 87, 094416.

34 A. K. Mishra, A. J. Darbandi, P. M. Leufke, R. Kruk and H. Hahn, J. Appl. Phys., 2013, 113, 033913.

35 J. Weissmüller, R. N. Viswanath, D. Kramer, P. Zimmer, R. Würschum and H. Gleiter, Science, 2003, 300, 312-315.

36 C. Lemier, S. Ghosh, R. N. Viswanath, G.-T. Fei and J. Weissmüller, MRS Proc., 2011, 876, R2.6.

37 C. Thiele, K. Dörr, L. Schultz, E. Beyreuther and W.-M. Lin, Appl. Phys. Lett., 2005, 87, 162512.

38 S. Dasgupta, B. Das, M. Knapp, R. A. Brand, H. Ehrenberg, R. Kruk and H. Hahn, Adv. Mater., 2014, 26, 4639-4644.

39 T. Tsuchiya, K. Terabe, M. Ochi, T. Higuchi, M. Osada, Y. Yamashita, S. Ueda and M. Aono, ACS Nano, 2016, 10, 1655-1661.

40 G. Benecke, W. Wagermaier, C. Li, M. Schwartzkopf, G. Flucke, R. Hoerth, I. Zizak, M. Burghammer, E. Metwalli, P. Müller-Buschbaum, M. Trebbin, S. Förster, O. Paris, S. V. Roth and P. Fratzl, J. Appl. Crystallogr., 2014, 47, 1797-1803.

41 J. Haetge, C. Suchomski and T. Brezesinski, Inorg. Chem., 2010, 49, 11619-11626.

42 S. Y. An, I. B. Shim and C. S. Kim, J. Magn. Magn. Mater., 2005, 290, 1551-1554.

43 W. B. White and B. A. DeAngelis, Spectrochim. Acta, Part A, 1967, 23, 985-995.

44 M. N. Iliev, V. G. Ivanov, N. D. Todorov, V. Marinova, M. V. Abrashev, R. Petrova, Y. Q. Wang and A. P. Litvinchuk, Phys. Rev. B: Condens. Matter Mater. Phys., 2011, 83, 174111.

45 A. K. Arora, M. Rajalakshmi, T. R. Ravindran and V. Sivasubramanian, J. Raman Spectrosc., 2007, 38, 604-617.

46 G. Gouadec and P. Colomban, J. Raman Spectrosc., 2007, 38, 598-603. 
47 E. C. Stoner and E. P. Wohlfarth, Philos. Trans. R. Soc., A, 1948, 240, 599-642.

48 W. C. Nunes, W. S. D. Folly, J. P. Sinnecker and M. A. Novak, Phys. Rev. B: Condens. Matter Mater. Phys., 2004, 70, 014419.

49 C. P. Bean and J. D. Livingston, J. Appl. Phys., 1959, 30, S120.

50 L. Neel, Ann. Geophys., 1949, 5, 99-136.

51 L. A. de Picciotto and M. Thackeray, Mater. Res. Bull., 1986, 21, 583-592.

52 S. Permien, S. Indris, U. Schürmann, L. Kienle, S. Zander, S. Doyle and W. Bensch, Chem. Mater., 2016, 28, 434-444.

53 J.-M. Tarascon, P. Poizot, S. Laruelle, S. Grugeon and L. Dupont, Nature, 2000, 407, 496-499.
54 X. Guo, X. Lu, X. Fang, Y. Mao, Z. Wang, L. Chen, X. Xu, H. Yang and Y. Liu, Electrochem. Commun., 2010, 12, 847-850.

55 D. Bresser, E. Paillard, R. Kloepsch, S. Krueger, M. Fiedler, R. Schmitz, D. Baither, M. Winter and S. Passerini, Adv. Energy Mater., 2013, 3, 513-523.

56 M. M. Thackeray, W. I. F. David and J. B. Goodenough, Mater. Res. Bull., 1982, 17, 785-793.

57 W. Zhou, Y. Wang, L. Zhang, G. Song and S. Cheng, Int. J. Electrochem. Sci., 2015, 10, 5061-5068.

58 M. Catti and M. Montero-Campillo, J. Power Sources, 2011, 196, 3955-3961.

59 C. J. Chen, M. Greenblatt and J. V. Waszczak, J. Solid State Chem., 1986, 64, 240-248. 